\title{
GESTÃo E AVALIAÇÃO EDUCACIONAL NA ESCOLA DE EDUCAÇÃO BÁSICA
}

\author{
Jacqueline Lima Honda ${ }^{(1)}$, Elianeth Dias Kanthack Hernandes ${ }^{(2)}$ \\ ${ }^{1}$ Discente do Curso de Pedagogia - Universidade Estadual Paulista (UNESP-Marília). ${ }^{2}$ Docente do Departamento Administração e \\ Supervisão Educacional - Universidade Estadual Paulista (UNESP-Marília) E-mail: honda.jacqueline@gmail.com'
}

\section{RESUMO}

Este estudo tem como objetivo identificar as aproximações e os tensionamentos entre a gestão escolar proposta pelas políticas governamentais e a gestão escolar realizada a partir da atuação cotidiana do trio gestor da escola. Participam deste estudo a diretora, a professora coordenadora e a supervisora de ensino de uma escola de educação básica do interior do estado de São Paulo. Para a coleta de dados está sendo realizado um levantamento dos referenciais teóricos já construídos na área da gestão escolar, levantamento de documentos da escola e entrevistas semi-estruturadas com o trio gestor. Espera-se que este estudo identifique os aspectos que aproximam e distanciam os resultados alcançados pela equipe gestora da escola, ao se auto-avaliar, daqueles resultados obtidos pela escola nos processos das avaliações educacionais. Os dados obtidos neste trabalho de investigação estão sendo analisados com base nos aspectos qualitativos.

Palavras - chave: Política Educacional; Gestão Escolar; Avaliação-externa; Auto-avaliação; Trio Gestor.

\section{MANAGEMENT SYSTEM AND EDUCATIONAL EVALUATION IN SCHOOL}

\section{ABSTRAT}

This research has been conducted with the objective of identifying the similarities and the differences between the school management system proposed by the government and the school management system applied on a daily basis by the school management team. This management team is composed by the school principal, the coordinator teacher, and the educational supervisor of a school in the inner state of Sao Paulo. Data is being collected researching the references already existed about the school management system, documents and files of the school, and by an interview with the management team. It is expected that this research will identify the close and the distant aspects between the evaluation of the management team about itself and the evaluation conducted by the school in the process of educational evaluations. The data obtained through this research job is being analyzed considering its quality aspects.

Keywords: Educational Politics, School Management System, External Evaluation, Self Evaluation, Manament Team 


\section{INTRODUÇÃO E OBJETIVO}

Para realizar este estudo foi priorizada a escolha de uma escola da rede estadual de ensino de um município do interior paulista como objeto de pesquisa. Esta escolha foi orientada pelo fato da escola, em 2007, ter participado voluntariamente e ter sido classificada entre as finalistas, de um prêmio de gestão promovido pela Secretaria de Estado da Educação de São Paulo. Esse prêmio previa como condição para participação, que a escola realizasse uma autoavaliação e propusesse um Plano Trienal de Ação Integrada entre Supervisor de Ensino e Diretor da escola, com vistas à qualificação do processo de aprendizagem oferecido. Para a premiação foram considerados dois itens importantes: as práticas inovadoras no ensino aos alunos e a melhoria na gestão escolar com a integração do diretor e supervisor de ensino.

Neste sentido, é necessário entender as iniciativas governamentais de intervenção nos rumos da educação básica. No Brasil, a implementação de sistemas avaliativos em larga escala costuma ser justificada mediante as limitações na qualidade do ensino oferecido aos alunos das escolas públicas, apoiada pelo discurso divulgado na mídia sobre essa temática. Hernandes (2011) demonstra isso quando relata que

desde a década de 1990 a escola de educação básica brasileira tem sido alvo de avaliações externas de diferentes denominações, mas com propósitos bastante próximos, tais como, o ENEM - Exame Nacional do Ensino Médio, SAEB - Sistema de Avaliação da Educação Básica, que se traduz em dois momentos avaliativos, o ANRESC e o ANEB, O PISA - Programa Internacional de Avaliação de Estudantes e 0 SARESP - Sistema de Avaliação do Rendimento escolar de São Paulo. (p. 3)

Mesmo assim, vale ressaltar, que esses sistemas de avaliação em larga escala implementados a partir da década de 1990, não atendem as reais necessidades das escolas públicas, mesmo tendo como principal justificativa para sua realização o redirecionamento das políticas públicas. Nessa direção, este estudo tem como um dos seus eixos de pesquisa a análise dos efeitos das avaliações em larga escala no cotidiano da equipe gestora da escola. Estudos vêm demonstrando que as vivências cotidianas e não cotidianas de cada unidade escolar sofrem a influência desses sistemas avaliativos, mas não são determinados por eles:

[...] as políticas produzem as diretrizes para o modo de existência da escola na condição dos sistemas e redes escolares, das variadas naturezas escolares atualmente existentes. No entanto, as diretrizes não se reproduzem concretamente tal qual são enunciadas e propostas ou mesmo impostas no plano superestrutural. A organização da esfera educacional de cada instituição escolar é única, mesmo que ela mantenha relações de identidade com outras instituições da mesma natureza (SILVA JR; FERRETTI, 2004, p. 58).

A cultura dos sistemas de avaliação externa em larga escala vem se solidificando no âmbito nacional. No entanto, ela muitas vezes não está articulada com os processos avaliativos dentro das escolas. Essa dualidade gera um descompasso entre as decisões políticas decorrentes, tanto nas decisões a serem tomadas no nível da micro estrutura (sala de aula), como na meso estrutura (escola), e na macro estrutura (SEE). Sobre isso, Arena (2006) esclarece e alerta:

Coletar dados, em processos de avaliação parece ser uma área em progressivo domínio. O problema é como compreender esses dados e que decisões tomar. Do mesmo modo que os responsáveis por políticas públicas têm dificuldades para formulá-las, orientados pelos dados, os professores têm seus limites para compreendê-los e tomar decisões metodológicas adequadas. 
Os dados só ganham sentido se forem compreendidos, mas para compreender é preciso ter formação teórica; do contrário, a avaliação não cumpre a sua finalidade: aperfeiçoar o modo de ensinar a todos os alunos. (p. 1).

Sendo assim, surgiram algumas questões envolvidas nesse processo de autoavaliação em que a instituição escolar se submeteu para participar do Prêmio de Gestão Educacional que demandaram a necessidade de serem investigadas, fazendo emergir assim, os seguintes questionamentos: a) Em que parâmetros a equipe escolar envolvida nesses processos avaliativos se baseou para se julgar com qualidades suficientes para concorrer ao prêmio de gestão e como realizou a sua autoavaliação? b) Como a equipe escolar se posiciona no seu cotidiano e na sua rotina administrativa e pedagógica, diante dos dados coletados nas avaliações internas e externas e das propostas daí decorrentes e que estão registradas no seu Plano de Ação Integrado?

Estas questões relativas aos aspectos técnicos e políticos da gestão educacional nortearam a definição do objeto de estudo neste trabalho de pesquisa que tem como tema a Gestão Escolar e as Avaliações Educacionais no cotidiano do trio gestor de uma escola de educação básica.

Desta forma, o que se pretende é que esse estudo permita uma reflexão sobre os desafios existentes no cotidiano dos educadores das instituições escolares de educação básica. Por sua natureza qualitativa, as contribuições que resultarão desta análise visam a um olhar mais amplo para as questões dos sistemas de avaliação externa e de como a escola encaminha os seus procedimentos na busca de atingir os objetivos por ela traçados. Para Maia (2000) existe a

necessidade de se pensar a prática da administração a partir do concreto e das necessidades dos dirigidos; na construção coletiva do projeto político-pedagógico da escola; da importância de se estudar as relações interpessoais nas escolas e da necessidade de se estudar a cultura da organização escolar através de estudos de caso. (p. 141).

Se existe a necessidade de pensar a prática da administração na concretude da ação gestora, é preciso explicitar o que está sendo chamado aqui de gestão educacional no âmbito da escola. Para isso, será utilizada a seguinte afirmação de Glatter:

Nunca consideramos a gestão como uma atividade puramente técnica, divorciada de valores e objetivos educacionais, um receio sentido por muitos dos atores escolares. A gestão deve ser tomada como uma atividade que pode facilitar e estruturar a definição dos objetivos e que pode igualmente dar-lhe expressão prática. (GLATTER, 1990, apud BARROSO, 1995, p.44)

É importante assumir desde já, que, na contramão da visão empresarial e tecnicista, a opção aqui assumida tem a perspectiva de que a gestão escolar se constitui em mediação para o alcance dos objetivos inerentes a função social da escola, devendo valorizar, para isso, a construção coletiva dos fins educacionais.

[...] o planejamento participativo e
coletivo se sobrepõe ao
planejamento tecnicista, individual e
solitário; sua construção deve ser
compreendida por todos como um
processo e um produto que dão
alento e ânimo para o
estabelecimento e o alcance das
finalidades da escola. (LIMA, 2007,
p. 95)

Esta reflexão pretende contribuir para a transformação da realidade, pois as pesquisas educacionais devem se constituir em fontes de apoio para a crítica e modificação da prática educativa até onde for o seu alcance. No entanto, fica evidenciada a pressuposta identificação de aspectos qualitativos e de eficácia da gestão 
escolar, por serem aspectos valorizados no regulamento do Prêmio Gestão, configurando os cuidados que devem ser tomados, na realização desta pesquisa.

Quando se quer medir a eficácia de uma escola, corre-se o risco de aprisionar a sua dinâmica numa perspectiva clássica e somativa, e o de acreditar que categorias préfabricadas possam captar uma realidade em constante movimento, que só existe no espaço de interação dos atores envolvidos. A problemática da eficácia evoluiu. Hoje, está-se abandonando a abordagem inicial, tecnicista e quantificadora, para se colocar em relação diferentes efeitos e características qualitativas, tais como o clima da escola, sua cultura ou sua ética. Essas características não podem ser captadas pelos métodos clássicos de observação pontual e externa, pois fazem parte de modos de funcionamento que só chegam a ser captados enquanto duram e observando-se as interações e as representações dos envolvidos. (THURLER, 1998, p. 175)

\section{METODOLOGIA}

A pesquisa está sendo desenvolvida em uma abordagem qualitativa que apresenta, entre outras, as características da historicidade e da contextualização com base no pressuposto que os conhecimentos são históricos e determinados e necessitam ser abordados e identificados e refletidos a partir dos tempos e espaços que são construídos (MACHADO, 2007). Foi aprovada pelo comitê de ética em pesquisa (CEP) sob o protocolo de $n^{\circ}$ 482/2012 estando em andamento e são sujeitos participantes deste estudo a diretora da escola, a professora coordenadora e a supervisora de ensino de uma unidade escolar de educação básica do interior do estado de São Paulo.

A proposta para a realização das entrevistas do tipo semi-estruturadas parte da concepção que essa forma de coleta de dados permite que se tenha um roteiro prévio básico e flexível, relacionado com a formação inicial, concepções e práticas gestoras. É importante lembrar que: "O processo de entrevista semiestruturada deve ser cuidadoso em todos os princípios [...] ela obtém resultados verdadeiramente valiosos se também 0 pesquisador tem amplo domínio do enfoque em estudo e da teoria que orienta seus passos." (TRIVIÑOS, 1987, p. 152) Isto porque, segundo Hernandes (2011), o Prêmio Gestão 2007, incitava os gestores a identificar suas potencialidades e fragilidades, e apoiados nisso, elaborar um Plano de Ação para os anos seguintes, com vistas nos avanços e melhorias na gestão escolar que gerassem impacto positivo no desempenho dos alunos.

\section{O levantamento dos resultados das} avaliações externas e os dados obtidos através da análise dos documentos serão articulados com aqueles colhidos por meio das entrevistas semiestruturadas. Desta forma, permitindo os conhecimentos necessários para 0 trabalho pedagógico na escola e assim como, dados para inovação dos estudos para os gestores. Com isso, pretende-se identificar padrões, que possam embasar o caráter qualitativo da função de gestor escolar por meio deste estudo de caso.

[...] Já na área de administração, o
estudo de caso tem servido para
estudar o funcionamento de uma
instituição e determinar focos de
mudanças ou de intervenção. O
estudo de caso aparece há muitos
anos nos livros de metodologia da
pesquisa educacional, mas dentro de
uma concepção bastante estrita, ou
seja, o estudo descritivo de uma
unidade, seja uma escola, um
professor, um aluno ou uma sala de
aula. (ANDRÉ, 1995, p.30)

Além disso, o que se pretende nesse estudo exige que se faça uma análise comparativa entre as propostas previstas no Plano de Ação Integrada Escola e Supervisão, elaborada em 2007, seus desdobramentos no 
Plano de Gestão em 2008, 2009 e 2010 (pautas, atas de reuniões, registros das orientações técnicas realizadas). E a partir daí relacionar com os resultados obtidos pelos alunos, no sistema de avaliação do Estado de S. Paulo.

\section{RESULTADOS PARCIAIS}

Tabela 1. ANÁLISE DO IDESP DA ESCOLA

\begin{tabular}{c|c|c|c|c|c|c|c}
\hline IDESP & META & IDESP & META & IDESP & META & IDESP & META \\
2007 & 2008 & 2008 & 2009 & 2009 & 2010 & 2010 & 2011 \\
\hline 4,06 & 4,19 & 4,96 & 5,06 & 5,00 & 5,10 & 4,90 & 5,01 \\
\hline \multicolumn{7}{l}{ ronte: site oficial da SEE/SP: www.educacao.sp.gov.br }
\end{tabular}

Fonte: site oficial da SEE/SP: www.educacao.sp.gov.br

Tabela 2. Índices de Fluxo Escolar - aprovação e reprovação da escola nos anos de abrangência do Plano de Ação Integrada Supervisor e Diretor do Prêmio Gestor

RESULTADOS

\begin{tabular}{c|c|c|c}
\hline ANO & APROVAÇÃO & REPROVAÇÃO & ABANDONO \\
\hline 2008 & $99,03 \%$ & $0,97 \%$ & 0 \\
\hline 2009 & $98,05 \%$ & $1,95 \%$ & 0 \\
\hline 2010 & $99 \%$ & $1 \%$ & 0 \\
\hline
\end{tabular}

Fonte: site oficial da SEE/SP: www.educacao.sp.gov.br

Tabela 3. Nível de proficiência em língua portuguesa. Dados SARESP.

\begin{tabular}{c|c|c|c|c}
\hline ANO & Abaixo básico & Básico & Adequado & Avançado \\
\hline 2008 & $13 \%$ & $36 \%$ & $37 \%$ & $14 \%$ \\
\hline 2009 & $13 \%$ & $31 \%$ & $41 \%$ & $15 \%$ \\
\hline 2010 & $14 \%$ & $42 \%$ & $25 \%$ & $19 \%$ \\
\hline
\end{tabular}

Fonte: site oficial da SEE/SP: www.educacao.sp.gov.br

Tabela 4. Nível de proficiência em matemática. Dados SARESP.

\begin{tabular}{c|c|c|c|c}
\hline ANO & Abaixo básico & Básico & Adequado & Avançado \\
\hline 2008 & $16 \%$ & $36 \%$ & $32 \%$ & $16 \%$ \\
\hline 2009 & $18 \%$ & $32 \%$ & $35 \%$ & $15 \%$ \\
\hline 2010 & $21 \%$ & $29 \%$ & $30 \%$ & $20 \%$ \\
\hline
\end{tabular}

Fonte: site oficial da SEE/SP: www.educacao.sp.gov.br

Tabela 5. IDEB da escola

\begin{tabular}{c|c|c|c|c|c}
\hline 2007 & META/2009 & 2009 & META/2011 & 2011 & META/2013 \\
\hline 5,1 & 5,3 & 6,1 & 5.6 & 6,5 & 5,9 \\
\hline
\end{tabular}

Fonte: www.sistemasideb.inep.gov.br/resultado

\section{DISCUSSÃO}

A tabela 1 traz dados sobre os resultados alcançados pela escola no IDESP Índice de Desenvolvimento da Educação de São
Paulo - entre 2007 a 2010. Esses dados permitem observar que a escola não atingiu as metas do IDESP em 2009 e 2010, os quais estão dentro do período de abrangência do Plano de Ação 
Integrada Supervisor e Diretor do Prêmio Gestor. Resultando, inclusive, em um rebaixamento em sua meta para o ano para o ano de 2011.

As tabelas 3 e 4 demonstram que houve um aumento no índice de alunos com desempenho abaixo do básico, tanto em Língua Portuguesa como em Matemática, no período de 2008 a 2010. Os índices de desempenho básico e adequado apresentaram decréscimo no componente curricular Matemática e na disciplina Língua Portuguesa o decréscimo fica evidenciado no nível básico. Vale destacar que no nível considerado avançado, ou seja, dos alunos que tiveram desempenho acima do esperado, ocorreu aumento no índice dos dois componentes curriculares no período em questão, ou seja, de 2008 a 2010, período de implementação do plano de ação integrada.

Os dados coletados e descritos permitem uma comparação nos resultados das metas das avaliações externas para 0 ano de 2009 (ver tabela 1 e 5), que demonstram certa discrepância nos resultados do IDESP aos do IDEB. No mesmo ano, o resultado obtido para o nível avançado de proficiência em português é crescente, já em matemática decresce (ver tabela 3 e 4). Da mesma forma, chama a atenção o índice de reprovação, em 2009, que atingiu $1,95 \%$, conforme a tabela 2 .

\section{CONCLUSÕES}

Ao proceder à análise dos dados acima descritos, alguns novos questionamentos passam a instigar e a direcionar a atenção dessa pesquisa: $O$ que realmente aproxima os resultados das avaliações externas realizada pela gestão escolar proposta pelas políticas governamentais com os resultados obtidos pela gestão escolar realizada a partir da atuação cotidiana do trio gestor da escola? Qual desses dois índices obtidos em 2009, pelas as avaliações externas (IDESP e IDEB), demonstram a realidade da escola, uma vez que são divergentes entre si? O tensionamento existente entre essas duas formas de avaliar/mensurar revela a fragilidade da escola ou dos sistemas de avaliações educacionais?

Os encaminhamentos de pesquisa realizados até 0 momento demonstraram o quanto ainda é necessário caminhar na compreensão das possíveis aproximações e tensionamentos existentes entre os sistemas de avaliação externa, a auto-avaliação da escola e o cotidiano do trio gestor. Lembrando que a teoria que embasa esse projeto de pesquisa e que já foi explicitada inicialmente tem servido como referencial para os encaminhamentos $e$ as opções feitas no percurso, mas nunca como filtro que impeça um contato real com o cotidiano da gestão educacional, via prática escolar. Com esse posicionamento, será possível compreender, de forma mais significativa, as reais possibilidades de interação do trio gestor, a partir das demandas ocasionadas pelas políticas de avaliação a que são submetidos.

\section{REFERÊNCIAS}

ANDRÉ, M. E. D. A. Etnografia da prática escolar. Campinas: Papirus, 1995.

ARENA, D. B. Século XXI exige novos modos de ler e pensar. v. 20 , n. 212 jun. 2006. Disponível em: <http://www.unesp.br/aci/jornal/212/suplea.php>. Acesso em: 12 dez. 2007

BARROSO, J. Para uma abordagem teórica da reforma da administração escolar: a distinção entre "direcção" e "gestão". Revista Portuguesa de Educação, Minho, v. 8, n. 1, p. 33-56, 1995.

LIMA, M. R. C. Paulo Freire e a administração escolar: a busca de um sentido. Brasília. Líber Livro, 2007.

LUDKE, M.; ANDRÉ, M. E. D. A. Pesquisa em educação: abordagens qualitativas. São Paulo: EPU, 1986.

HERNANDES, E. D. K. Resultados de avaliações externas e internas em escolas da rede pública de São Paulo: aproximações ou 
contradições? Texto para ANPAE. Universidade Estadual Paulista, Faculdade de Filosofia e Ciências. Marília, 2011.

MAIA, G.Z.A. Gestão escolar: implicações para um ensino de qualidade. 2000. 211 f. Tese (Doutorado em educação) - Faculdade de Filosofia e Ciências - Universidade Estadual Paulista, Marília.

MACHADO, L. M. Considerações sobre a natureza do trabalho científico. In: LABEGALINI, A.C.F.B.; MAIA, G. Z. A.; MACHADO, L.M. (orgs.). Pesquisa em Educação: passo a passo. Marília: Edições M3T Tecnologia e Educação, 2007.

SILVA JR., J. R.; FERRETTI, C. J. O institucional, a organização e a cultura da escola. São Paulo: Xamã, 2004.

TRIVIÑOS, A. N. S. Introdução à pesquisa em Ciências Sociais: a pesquisa qualitativa em educação. São Paulo. Atlas, 1987.

THURLER, M. G. A eficácia das escolas não se mede: ela se constrói, negocia-se, pratica-se e se vive. São Paulo: FDE, 1998. p. 175-192. (Série Ideias n. 30). 